\title{
Pre-exposure prophylaxis for South African adolescents: What evidence?
}

\author{
L-G Bekker, MB ChB, DTMH, DCH, FCP (SA), PhD; K Gill, MB ChB, DA, Dip Pall Med; M Wallace, BSocSci Hons, MSc, PhD
}

Desmond Tutu HIV Centre, Institute of Infectious Disease and Molecular Medicine, University of Cape Town, South Africa

Corresponding author: L-G Bekker (linda-gail.bekker@hiv-research.org.za)

Adolescents and young women, particularly in South Africa, are at increased risk of HIV acquisition. To date, we have had limited primary prevention options to offer. Oral pre-exposure prophylaxis (PrEP) is an additional prevention modality that has now been proven to reduce HIV acquisition in those who take it consistently during periods of HIV infection exposure. We review the PrEP evidence in adolescents and highlight some of the research gaps. Our recommendation is to increase the number of demonstration projects and other scale-up opportunities to offer oral PrEP to at-risk adolescents, and monitor carefully to answer the outstanding questions.

S Afr Med J 2015;105(11):907-911. DOI:10.7196/SAMJ.2015.v105i11.10222

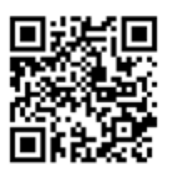

Adolescents and youth constitute one-third of populations in sub-Saharan Africa, and despite having some of the highest HIV incidence and prevalence rates in the world, we have very few prevention interventions to offer this key population. ${ }^{[1]}$ Since the first realisation that much HIV transmission was occurring via heterosexual and homosexual sex, the primary prevention options have consisted only of sexual abstinence, including sexual debut delay, monogamous sex with an individual of known HIV-negative status, or consistent condom use. While female condoms are available, most reliance has been on male condoms.

\section{Adolescents and HIV}

Adolescence is a period of transition from childhood to adulthood, spanning the years $10-19$, although neurodevelopmental specialists argue that brain and therefore psychological modelling continues until at least 25 years of age. ${ }^{[2]}$ It is a period of immense physical, psychological, social and emotional growth and is characterised by many opportunities for experimentation, new experiences and consequent vulnerabilities. ${ }^{[3]}$ Yet it is a time also characterised by limited access to information and appropriate health and prevention services, leading to an increased risk of acquisition of HIV and other infections ${ }^{[4,5]}$ Navigating this transition successfully is highly dependent on individual efficacy and resilience, as well as input and support from family, friends, schools and communities. ${ }^{[6]}$

Given these vulnerabilities, both sexual abstinence and monogamy have limited application throughout the period of adolescence and are impractical as exclusive HIV prevention interventions for youth.

In generalised epidemics, females experience much higher levels of HIV infection than their male counterparts in late adolescence and throughout the early reproductive years. ${ }^{[1]}$ While behaviour is an important driver of infection, the risk behaviours of South African (SA) adolescents are not necessarily greater than those of adolescents elsewhere. ${ }^{[7]}$ Biological differences partly explain this apparent contradiction, but social and structural factors also instigate and maintain the risk behaviours that ultimately drive the adolescent epidemic in SA. ${ }^{[8,9]}$

Much has been written about the high levels of sexual coercion and violence in SA. ${ }^{[10,11]}$ Power inequality and intimate partner violence decrease condom use and increase the risk of HIV infection in adolescent females and young women. ${ }^{[1,12]}$ Inequality in sexual relationships is further amplified when there is a significant age difference between the two parties. Older men are more likely to be infected with HIV than adolescents, and this may be contributing to sudden increases in HIV acquisition in adolescent females as they commence relationships with older men.

In 1990, Stein ${ }^{[13]}$ advocated user-dependent prevention methods, particularly female-initiated and managed ones. It was thought that vaginal microbicides could fill this prevention gap. In 2015, we do not yet have a licensable vaginal microbicide, but oral pre-exposure prophylaxis (PrEP) is certainly a viable alternative. Oral PrEP involves the administration of a single antiretroviral (ARV) agent, or dual agents, to HIV-negative individuals prophylactically, to protect them from infection should they be exposed to an infective source.

Following the first study of PrEP efficacy, among men who have sex with men (MSM) and transgendered women (TGW) and reported in 2010, the concept of a daily pill (emtricitabine (FTC) and tenofovir (TDF), sold as Truvada) to prevent HIV infection has become increasingly evident as a useful additional biomedical intervention to offer to individuals in conjunction with regular testing, counselling, condoms and safe lubricants. ${ }^{[14]}$

\section{PrEP evidence}

To date there have been ten randomised controlled trials (RCTs) of TDF-based PrEP reporting HIV outcomes. ${ }^{[15]}$ PrEP was effective for both men and women. The studies have involved more than 17000 people and have demonstrated an overall reduction in HIV acquisition risk of $51 \%$ (women relative risk (RR) 0.57 ; $95 \%$ confidence interval (CI) $0.34-0.94$, and men RR 0.38 ; 95\% CI 0.2 $0.6)$. Three studies in which there was high adherence to the study product ( $>70 \%$ of drug detection) showed that PrEP was most efficacious and also that HIV infection was significantly reduced in those studies in which drug detection levels were moderate (41-70\% detection). Unfortunately in the two studies with lowest adherence $(<40 \%$ detection), involving heterosexual women in southern and East Africa, PrEP had no effect. ${ }^{[15-17]}$ The reasons for the particularly low uptake and use of oral PrEP in these two studies have been speculated on elsewhere and a range of potential reasons have been suggested, 
structural, behavioural and/or psychological. ${ }^{[18]}$ Unfortunately this has led to some controversy around the effectiveness of oral PrEP in black African women. It is important to note, however, that two of the three studies considered by the US Food and Drug Administration (FDA) prior to licensure of PrEP as a prevention modality included women from Uganda, Kenya and Botswana. ${ }^{[15]}$ As a consequence, in 2012 the FDA approved TDF/FTC PrEP for men and women at risk of sexual acquisition of HIV. The South African Medicines Control Council is currently considering this ARV combination for a similar indication.

The critical component of PrEP's success is that people actually take it. The current recommendation in all guidelines is to aim for a daily dose of the single combination tablet during periods when sexual HIV exposure is possible. ${ }^{[15,19]}$ The scientific rationale is that systemic drug levels will influence tissue drug levels at the site where HIV contact may occur. This applies to vaginal, penile and rectal mucosa. As a result of this extensive evidence base, the World Health Organization (WHO) has just included oral PrEP as an additional prevention choice as part of combination prevention for people at substantive risk in its 2015 comprehensive treatment and care guidelines. ${ }^{[15]}$ Table 1 lists all ten randomised controlled trials to date and highlights those in which age was delineated.

In addition, for some time the WHO has recommended demonstration projects in various populations and settings to try to delineate the best distribution platforms in both high- and lowerincome settings.

\section{Adolescents and PrEP}

There is a dearth of literature examining attitudes to oral PrEP use among adolescents globally. This scarcity is even more pronounced in sub-Saharan Africa. Most of the research on attitudes among youth and adolescents has been done in the USA, with young men who have sex with men (YMSM). Table 2 describes some of the cited literature.

Generally, knowledge of PrEP was limited, $27-38 \%$ of study participants having heard of PrEP and $1-1.5 \%$ having used it, ${ }^{[2,21]}$ with many expressing a desire for more information. ${ }^{[22,23]}$ Knowledge was found to be associated with higher education, recent HIV testing and gay identity, ${ }^{[21]}$ as well as increased age, having had a sexually transmitted infection and having health insurance. ${ }^{[20]}$ In all studies, there was generally a positive attitude towards PrEP and a willingness

Table 1. Randomised controlled trials comparing oral PrEP with placebo

\begin{tabular}{|c|c|c|c|c|c|}
\hline $\begin{array}{l}\text { Trial name and } \\
\text { location }\end{array}$ & No. enrolled & Age (years), median (range) & Study population & No. aged $<25$ years & Efficacy outcome \\
\hline $\begin{array}{l}\text { FEM-PrEP } \\
\text { Daily }\end{array}$ & 2120 & $23(18-35)$ & WSM & 1213 & Stopped for futility \\
\hline $\begin{array}{l}\text { iPrEx } \\
\text { Daily }\end{array}$ & 2499 & $27(18-67)$ & MSM/TGW & $\begin{array}{l}1 \mathrm{153} \text {, no significant } \\
\text { difference in ages }\end{array}$ & $44 \%$ \\
\hline $\begin{array}{l}\text { Partners PrEP } \\
\text { Daily }\end{array}$ & 4758 & $33 \mathrm{~W}, 34 \mathrm{M}(18-65)$ & Serodiscordant couples & $\begin{array}{l}583, \text { no significant } \\
\text { difference between } \\
\text { women }<25 \text { and }>25 \\
\text { years }\end{array}$ & $75 \%$ \\
\hline $\begin{array}{l}\text { TDF2 } \\
\text { Daily }\end{array}$ & 1219 & $25(18-39)$ & $\begin{array}{l}\text { Heterosexual men and } \\
\text { women }\end{array}$ & $<21$ yrs: 25 & $62 \%$ \\
\hline West African study & 536 & Unknown & Women & Unknown & $\begin{array}{l}65 \% \text { efficacy } \\
\text { Stopped early for } \\
\text { structural reasons }\end{array}$ \\
\hline $\begin{array}{l}\text { Voice, MTN-003 } \\
\text { Daily gel v. oral }\end{array}$ & 5029 & $25(18-45)$ & WSM & Unknown & Stopped for futility \\
\hline $\begin{array}{l}\text { US safety study, } \\
\text { CDC } 4323 \\
\text { Daily }\end{array}$ & 400 & $39(18-60)$ & MSM & Unknown & $\begin{array}{l}\text { TVD detected in } \\
50 \% \text { of people who } \\
\text { seroconverted and } \\
\text { in } 81 \% \text { of those } \\
\text { who did not }\end{array}$ \\
\hline $\begin{array}{l}\text { Ipergay } \\
\text { Pericoital }\end{array}$ & 414 & $35(29-43)$ & MSM & & $\begin{array}{l}86 \% \text { efficacy } \\
\text { Placebo arm } \\
\text { stopped early } \\
\text { owing to positive } \\
\text { results }\end{array}$ \\
\hline $\begin{array}{l}\text { Bangkok, IDU } \\
\text { study } \\
\text { Daily }\end{array}$ & 2413 & $31(20-60)$ & PWID & $1033<30$ & $49 \%$ \\
\hline $\begin{array}{l}\text { IAVI, Kenya } \\
\text { Pericoital v. daily }\end{array}$ & 72 & $26(18-46)$ & MWSM & Unknown & $\begin{array}{l}\text { MEMS cap } \\
\text { adherence } 83 \% \text { in } \\
\text { daily arm }\end{array}$ \\
\hline
\end{tabular}


Table 2. PrEP-related research

\begin{tabular}{|c|c|c|}
\hline Reference & Type of research & Population studied \\
\hline Bauermeister et al. ${ }^{[20]}$ & Quantitative & YMSM (18 - 24 years) \\
\hline Kubicek et al. ${ }^{[22]}$ & Qualitative & YMSM (18 - 25 years) \\
\hline Pérez-Figueroa et al. ${ }^{[23]}$ & Qualitative & YMSM (18 - 21 years) \\
\hline Rucinski et al. ${ }^{[21]}$ & Quantitative & YMSM (18 - 40 years) \\
\hline Smith et al. ${ }^{[24]}$ & Qualitative & YMWSM (18 - 24 years) \\
\hline Mustanski et al.$^{[25]}$ & Quantitative & MSM (16 - 20 years) \\
\hline
\end{tabular}

to use it. Nonetheless, barriers to use were raised. One of the most significant concerns was possible side-effects of the drug, ${ }^{[22,24]}$ with $36 \%$ of participants in one study reporting that they would not use PrEP for this reason. ${ }^{[20]}$ Other barriers included the regimen burden and uncertainty regarding ability to adhere to a daily pill and regular check-ups, ${ }^{[23-25]}$ the partial efficacy of $\operatorname{PrEP},{ }^{[24,25]}$ access and cost issues ${ }^{[2,23]}$ and low perceived risk of HIV infection. ${ }^{[24]}$ In addition, stigma was identified as a potential barrier in terms of being seen taking HIV treatment medication, as well as the association of taking PrEP with high-risk sexual behaviour and groups. ${ }^{[23,24]}$ In contrast, others reported that they would be proud to take $\operatorname{PrEP}^{[24]}$ and that it was well suited to certain situations and people (serodiscordant couples, people who found it difficult to adhere to condom use, those in casual sexual relationships). ${ }^{[22,23,25]}$

Given the differences in social context between YMSM in the USA and adolescents in SA, these data are not necessarily applicable to SA. Very little research has examined these issues in SA adolescents so far. Acceptability, interest, concerns and preferences regarding ARV-based prevention in pill, gel and injectable format have been explored in young women in SA and female sex workers and serodiscordant couples in Kenya. ${ }^{[2]}$ With an overall sample of 36, two focus groups with adolescent girls (14 - 17 years) and two with young women (18 - 24 years) were conducted in SA. All groups expressed strong interest in PrEP use. Interestingly, adolescent girls felt that PrEP would be obtainable with privacy more easily than condoms, enhancing its appeal. Young women were enthusiastic, but concerned about the interactions with drugs and alcohol and also the challenges of adherence while under the influence of substances (often preceding sex). In addition, they speculated that ultimately products would not be used with trusted partners (much like condoms), thus making them no more effective. In terms of formulation preference, adolescents noted that all formulations presented adherence challenges. They felt that daily pills could be taken or used more easily than vaginal gel (coitally dependent), as sex was difficult to predict, but had concerns around swallowing pills and the impact on urine smell. Some preferred the coitally dependent gel as a less burdensome regimen, although they felt that it would be unpleasant to insert and might smell, while injections if given in depot form were viewed as painful. Among young women, those who preferred pills felt that they were safer than injections and more private than gel use, but others had concerns about daily pill adherence. Some preferred the injection owing to familiarity with the injectable contraceptive, and felt it was safer, longer lasting, private and difficult to forget about. One other study examined willingness to use PrEP among young women in SA as part of a global survey of 1790 participants from seven countries; ${ }^{[27]} 124$ young women (18 24 years) from SA participated. In contrast to most other subgroups, side-effects, cost and the need for regular HIV testing posed higher barriers to use in this subgroup. With regard to the relative importance of key PrEP attributes, young SA women rated route of administration most highly, followed by frequency of HIV testing, time spent obtaining PrEP, dispensing site and frequency of pick up. A bimonthly injection in the buttocks was most preferred, with HIV testing 6-monthly. These studies are limited by their hypothetical nature, but highlight the importance of choice and convenience in meeting the needs of different young women in SA.

All ten randomised controlled PrEP studies exclusively included people aged $>18$ years, and only three stratified trial populations into younger $\left(<25\right.$ years) and older. ${ }^{[15]}$ In those studies, sexual and other behaviours were riskier in the younger group, but adherence and subsequently PrEP effectiveness were reduced. One of the studies in this group is the Global iPrEx study performed in MSM. ${ }^{[14]} \mathrm{A}$ subanalysis of the younger participants (18 - 24 years), who made up almost half of the overall cohort, demonstrated that those aged $<25$ years were 3.74 times ( $95 \%$ CI 2.40 - 5.82) less likely to show drug detection in the blood $(p<0.001)$ compared with those aged $>25$ years. The incidence of HIV per 100 person-years among young MSM was 3.06 in the TDF/FTC group and 4.24 in the placebo group. ${ }^{[28]}$

The US-based Adolescent Trials Network (ATN) has reported on feasibility, safety and adherence in PrEP studies in the young MSM population (18 - 22 years) in the USA as part of Project PrEPare. ATN 082 enrolled 68 individuals (mean age 19.9 years) in a placebocontrolled study in which 58 individuals were randomised to a behavioural intervention alone or the behavioural intervention either with TDF/FTC or placebo. ${ }^{[29]}$ Self-reported medication adherence averaged $62 \%$ (range $43-83 \%$ ), while rates of detectable plasma tenofovir ranged from $63.2 \%$ to $20 \%$ (weeks 4 - 24). The most commonly reported reasons for missing doses included being away from home (60\%), forgetting (50\%) and being too busy (47\%). ${ }^{[29]}$

ATN 110 enrolled 200 MSM aged 18 - 22 years who were offered the same behavioural intervention with oral PrEP but in an openlabel manner. PrEP was well tolerated with minimal side-effects. While PrEP drug levels commensurate with a prevention-efficacious dose of $>4$ pills per week were seen in $>50 \%$ of blood samples at week 4 , this had reduced by week 48 , with marked differences in consistent adherence by ethnicity. Participants who reported condomless sex were more likely to be adherent. ${ }^{[30]}$ This study has an ongoing 'brother' study in 15 - 19-year-olds, and adherence and feasibility data from this adolescent cohort are eagerly awaited in 2016 (ATN 113).

An optimistic picture is emerging from the open-label extensions of the randomised trials and the demonstration studies now in the field, the most promising of these being the recent PROUD (MSM) and Partners PrEP open-label extensions and demonstration studies (discordant black African couples). ${ }^{[31-33]}$

A recent study known as ADAPT HPTN 067, conducted in Cape Town, SA, randomised 179 heterosexual women into three arms of self-administered daily, event-driven and intermittent TDF/FTC PrEP over a 24-week period. ${ }^{[34]}$ The 'coverage' of sexual events with PrEP taking was measured along with actual PrEP blood levels. The coverage of sexual events, reported adherence and blood drug levels of the women in the daily arm were better than those in the other intermittent arms. In addition, overall adherence in the daily arm was good at 10 and 30 weeks of follow-up, and similar between younger and older participants. ${ }^{[34]} \mathrm{PrEP}$ is feasible in younger individuals.

These recent open-label studies suggest that if individuals are told that an intervention such as PrEP works, not only are they more likely to take it, but also those most at risk self-identify.

TDF and FTC are two ARV agents with a relatively clean safety profile. With many patient-years of exposure worldwide, both are regarded as a safe combination in people on HIV treatment, and they form part of the triple, single-pill antiviral agent currently 
being dispensed to millions of HIV-positive South Africans. Of note, all the above PrEP studies in normal healthy individuals also had an unremarkable safety profile. Adverse events were mild and minimal, occurring in the minority and mostly in the first month of exposure. These self-limiting adverse events included headaches, bloating, nausea and mild diarrhoea. Some of the studies noted non-progressive, subclinical declines in renal functioning and bone mineral density, none of which caused clinical events. ${ }^{[14]}$ Another theoretical risk is that of HIV-resistance mutations occurring when breakthrough HIV infection occurs in the face of inadequate PrEP drug levels. This phenomenon has not occurred in the RCTs to date. ${ }^{[15]}$ As PrEP scale-up starts in earnest, adverse events, safety and the threat of resistance will need to be closely monitored.

If a pill a day in the form of oral PrEP is an intervention that can be used by young women and men discreetly and independently, and can significantly reduce HIV acquisition, we urgently need to find out how to make this available to the young SA individuals who would benefit most, and in such a way that would derive the greatest impact. ${ }^{[3,36]}$

\section{Recommendations}

One of the quickest ways to get oral PrEP into the adolescent community safely and effectively would be to initiate a number of projects in a number of settings and from a variety of distribution

\section{Table 3. Knowledge gaps in PrEP provision for adolescents}

Questions in provision of oral PrEP to adolescents

Behavioural

Acceptability of PrEP

Willingness to use daily PrEP

Adherence to/persistence with programme (monitoring, testing, counselling)

Adherence to daily pills

Stigma

Sexual disinhibition with condom migration

Biomedical

Tolerability

Toxicities - impact on bone mineralisation

More STIs? - mucosal activation

More frequent sex, sex partners

Less frequent sex? Loading dose

Size and smell of pills

Increased unwanted pregnancy and STIs

Structural

Which health platform? SRH, ANC, FP, PHC

Regular testing

Adolescent-friendly services

Confidentiality/privacy

Social

Enablers to assist with daily adherence, e.g. SMS messaging

Enablers to assist with integration into programme, e.g. social media/networks

STIs = sexually transmitted infections; $\mathrm{SRH}=$ sexual and reproductive health; $\mathrm{ANC}=$ antenatal clinic; $\mathrm{FP}=$ family planning; $\mathrm{PHC}=$ primary healthcare $\mathrm{SMS}=$ text message. platforms involving SA adolescent users. Unfortunately, of the many demonstration projects around the world that are currently underway or imminently planned, very few involve adolescent populations. ${ }^{[37]}$

One open-label study called Pluspills is part of the broader CHAMPS-SA project of the Desmond Tutu HIV Foundation and is currently enrolling 150 young men and women aged 15 - 19 years in Cape Town and Soweto. Data on acceptability, use and adherence will be available in October 2016. Another HPTN-sponsored study is also undergoing regulatory review and will involve 400 young black African women aged 15 - 24 years. It is expected to launch by 2016 .

In addition, a number of agencies are considering combination prevention projects among adolescent girls and young women that could inform scale-up of PrEP in southern and eastern Africa. These include a multi-institutional project funded by USAID and the very exciting DREAMS project spearheaded by PEPFAR and various private funders in PEPFAR-sponsored African countries. ${ }^{[38,39]}$

There are a number of gaps in our knowledge of how best to utilise this intervention among adolescents, and these could be answered by well-constructed and monitored field projects. Table 3 lists some of these outstanding questions.

\section{Future directions}

Oral PrEP is available and has a growing evidence base for its wider deployment. Unlike ARV treatment, oral PrEP is an intervention that individuals would need and use only during periods of HIV risk. The analogy is malaria prophylaxis, where antimalarial prophylactic agents are only taken during periods of exposure to potentially infected mosquitoes. In the case of adolescents this may cover the periods of sexual experimentation and when permanent sexual partners have not yet been established and partner status is unknown, which it is hoped would also align with the highest incidence rates.

In addition, other longer-acting modalities are in clinical development that may assist with daily adherence, something that has been identified as difficult in adolescent populations. Some of these modalities include a vaginal ring that needs only monthly administration, and long-acting injectable agents that may be dispensed every 2 months. Table 4 lists some of these PrEP modalities and when efficacy data to support their use may be available. The analogy is that of contraception, where both choice of modality and options for prolonged dosing intervals have been shown to increase adherence and effectiveness.

Table 4. Some of the newer alternative modalities in the pipeline

\begin{tabular}{|c|c|c|}
\hline Modality & Study & Results expected \\
\hline \multirow[t]{2}{*}{ Dapivirine vaginal ring } & $\begin{array}{l}\text { ASPIRE MTN } 020 \\
\text { Phase } 3\end{array}$ & Q4 2015/Q1 2016 \\
\hline & $\begin{array}{l}\text { The Ring Study } \\
\text { IPM } 027 \\
\text { Phase } 3\end{array}$ & Q4 2016 \\
\hline $\begin{array}{l}\text { Cabotegravir LA PrEP } \\
\text { 8-week injectable PrEP }\end{array}$ & $\begin{array}{l}\text { HPTN } 077 \\
\text { Phase 2a }\end{array}$ & Q3 2017 \\
\hline $\begin{array}{l}\text { TMC278 (rilpivirine) } \\
\text { LA PrEP } \\
\text { 8-week injectable PrEP }\end{array}$ & $\begin{array}{l}\text { HPTN } 076 \\
\text { Phase 2a }\end{array}$ & Q4 2017 \\
\hline $\begin{array}{l}\text { Cabotegravir LA PrEP v. } \\
\text { oral PrEP v. placebo }\end{array}$ & $\begin{array}{l}\text { HPTN } 083 \\
\text { Phase } 2 b\end{array}$ & To be commenced \\
\hline
\end{tabular}




\section{Conclusions}

Apart from sexual abstinence, to date we have been able to offer young women only the male latex condom as protection against HIV infection. Given some of the difficulties described above, it is less than surprising that in 2015 we see incidence rates among young SA women that are the highest in the world. Young people, and especially young women, need more prevention options to protect themselves. ${ }^{[36]}$ Oral PrEP certainly is one such modality that has great promise. Offering this intervention to our adolescent and young adult population has the potential to make a significant dent in our epidemic.

\section{References}

1. Dellar RC, Dlamini S, Abdool Karim Q. Adolescent girls and young women: Key populations for HIV epidemic control. J Int AIDS Soc 2015;18(Suppl 1):19408. [http://dx.doi.org/10.7448/IAS.18.2.19408]

2. World Health Organization. Health for the World's Adolescents: A Second Chance in the Second Decade. Geneva: WHO, 2014. http://apps.who.int/adolescent/second-decade/files/1612_MNCAH HWA_Executive_Summary.pdf (accessed 15 July 2014).

3. Bekker L-G, Johnson L, Wallace M, Hosek S. Building our youth for the future. J Int AIDS Soc 2015;18(Suppl 1):20027. [http://doi.org/10.7448/IAS.18.2.20027]

4. Gulliver A, Griffiths KM, Christensen H. Perceived barriers and facilitators to mental health helpseeking in young people: A systematic review. BMC Psychiatry 2010;10(1):113. [http://dx.doi. rg/10.1186/1471-244X-10-113]

5. Delany-Moretlwe S, Cowan F, Busza J, Bolton-Moore C, Kelley K, Fairlie L. Providing comprehensive health services for young key populations: Needs, barriers and gaps. J Int AIDS Soc 2015;18(Suppl 1):19833. [http://dx.doi.org/10.7448/IAS.18.2.19833]

6. DiClemente RJ, Salazar LF, Crosby RA, Rosenthal SL. Prevention and control of sexually transmitted infections among adolescents: The importance of a socio-ecological perspective - a commentary. Public Health 2005;119(9):825-883. [http://dx.doi.org/10.1016/j.puhe.2004.10.015]

7. Pettifor AE, Levandowski BA, Macphail C, et al. A tale of two countries: Rethinking sexual risk for HIV among young people in South Africa and the United States. J Adolesc Health 2011;49(3):237-243. [http://dx.doi.org/10.1093/ije/dyn131]

8. Eaton L, Flisher AJ, Aarø LE. Unsafe sexual behaviour in South African youth. Soc Sci Med 2003;56(1):149-165. [http://dx.doi.org/10.1016/S0277-9536(02)00017-5]

9. Jaspan HB, Berwick JR, Myer L, et al. Adolescent HIV prevalence, sexual risk, and willingness to participate in HIV vaccine trials. J Adolesc Health 2006;39(5):642-648. [http://dx.doi.org/10.1016/j. adohealth.2006.05.016]

10. Wood K, Maforah F, Jewkes R. 'He forced me to love him': Putting violence on adolescent sexual health agendas. Soc Sci Med 1998;47(2):233-242. [http://dx.doi.org/10.1016/S0277-9536(98)00057-4]

11. Jewkes RK, Dunkle K, Nduna M, Shai N. Intimate partner violence, relationship power inequity, and ncidence of HIV infection in young women in South Africa: A cohort study. Lancet 2010;376(9734):414. [http://dx.doi.org/10.1016/S0140-6736(10)60548-X]

12. Pettifor AE, Measham DM, Rees HV, Padian NS. Sexual power and HIV risk, South Africa. Emerg Infect Dis 2004;10(11). [http://dx.doi.org/10.3201/eid1011.040252]

13. Stein Z. HIV prevention: The need for methods women can use. Am J Public Health 1990;80(4):460462. [http://dx.doi.org/10.2105/AJPH.80.4.460]

14. Grant RM, Lama JR, Anderson PL, et al. Preexposure chemoprophylaxis for HIV prevention in men who have sex with men. N Engl J Med 2010;363(27):2587-2599. [http://dx.doi.org/10.1056/ NEJMoa1011205]

15. World Health Organization.Guideline on when to start antiretroviral therapy and on pre-exposure prophylaxis for HIV. 2015. WWW.who.int (accessed 1 October 2015).

16. Van Damme L, Corneli A, Ahmed K, et al. Preexposure prophylaxis for HIV infection among African women. N Engl J Med 2012;367(5):411-422. [http://dx.doi.org/10.1056/NEJMoa1202614]

17. Marrazzo JM, Ramjee G, Richardson B, et al. Tenofovir-based preexposure prophylaxis for HIV infection among African women. N Engl J Med 2015;372:509-518. [http://dx.doi.org/10.1056/ NEJMoal402269]

18. Heffron R, Baeten J. Tenofovir-based oral PrEP prevents HIV infection among women. Curr Opin HIV AIDS (in press).
19. Smith DK, Koenig LJ, Martin M. Preexposure Prophylaxis for the Prevention of HIV Infection in the United States - 2014 Clinical Practice Guideline. US Public Health Service CDC, 2014:67.

20. Bauermeister JA, Meanley S, Pingel E, et al. PrEP awareness and perceived barriers among single young men who have sex with men in the United States. Curr HIV Res 2013;11(7):520-527. [http:// dx.doi.org/10.2174/1570162X12666140129100411]

21. Rucinski KB, Mensah MP, Sepkowitz KA, et al. Knowledge and use of pre-exposure prophylaxis among an online sample of young men who have sex with men in New York City. AIDS Behav 2013;17(6):2180-2184. [http://dx.doi.org/10.1007/s10461-013-0443-y]

22. Kubicek K, Arauz-Cuadra C, Kipke MD. Attitudes and perceptions of biomedical HIV prevention methods: Voices from young men who have sex with men. Arch Sex Behav 2015;44(2):487-497. [http:// dx.doi.org/10.1007/s10508-014-0398-8]

23. Pérez-Figueroa RE, Kapadia F, Barton S, et al. Acceptability of PrEP uptake among racially/ethnically diverse young men who have sex with men: The P18 Study. AIDS Educ Prev 2015;27(2):112-125. [http://dx.doi.org/10.1521/aeap.2015.27.2.112]

24. Smith DK, Toledo L, Smith D-F, et al. Attitudes and program preferences of African-American urban young adults about pre-exposure prophylaxis (PrEP). AIDS Educ Prev 2012;24(5):408-421. [http:// dx.doi.org/10.1521/aeap.2012.24.5.408]

25. Mustanski B, Johnson AK, Garafalo R, et al. Perceived likelihood of using HIV pre-exposure prophylaxis medications among young men who have sex with men. AIDS Behav 2013;17(6):21732179. [http://dx.doi.org/10.1007/s10461-012-0359-y]

26. Mack N, Evens E, Tolley EE, et al. The importance of choice in the rollout of ARV-based prevention to user groups in Kenya and South Africa: A qualitative study. J Int AIDS Soc 2014;17(Suppl 2):19157. [http://dx.doi.org/10.7448/IAS.17.3.19157]

27. Eisingerich AB, Wheelock A, Gomez G, et al. Attitudes and acceptance of oral and parentera HIV preexposure prophylaxis among potential user groups: A multinational study. PLoS One 2012;7(1):e28238. [http://dx.doi.org/10.1371/journal.pone.0028238]

28. Bekker L-G, Glidden DV, Hosek S, et al. PrEP in young MSM: Needs and challenges. Presented at the 20th Conference on Retroviruses and Opportunistic Infections (CROI), 3 - 6 March 2013, Atlanta USA. http://retroconference.org (accessed 17 October 2015).

29. Hosek S, Siberry G, Bell M, et al. Project PrEPare (ATN082): The acceptability and feasibility of an HIV pre-exposure prophylaxis (PrEP) trial with young men who have sex with men (YMSM). J Acquir Immune Defic Syndr 2013;62(4):447-456. [http://dx.doi.org/10.1097/QAI.0b013e3182801081]

30. Hosek S, Rudy B, Landovitz R, et al. An HIV pre-exposure prophylaxis demonstration project and safety study for young men who have sex with men in the United States (ATN 110). J Int AIDS Soc 2015;18.

31. Grant R, Anderson PL, MacMahan V, et al. Uptake of pre-exposure prophylaxis, sexual practices, and HIV incidence in men and transgender women who have sex with men: A cohort study. Lancet Infect Dis 2014;14(9):820-829. [http://dx.doi.org/10.1016/S1473-3099(14)70847]

32. Baeten J, Heffron R, Kidoguchi L. Near elimination of HIV transmission in a demonstration project of PrEP and ART. Presented at the Conference on Retroviruses and Opportunistic Infections (CRO 2015), Seattle, USA, 23-26 February 2015.

33. McCormack S, Dunn DT, Desai M, et al. Pre-exposure prophylaxis to prevent the acquisition of HIV-1 infection (PROUD): Effectiveness results from the pilot phase of a pragmatic open-label randomised trial. Lancet 2015. Published online September 10, 2015. [http://dx.doi.org/10.1016/ S0140-6736(15)00056-2]

34. Bekker LG, Hughes J, Amico R, et al. HPTN 067/ADAPT Cape Town: A comparison of daily and nondaily PrEP dosing in African women. Presented at the Conference on Retroviruses and Opportunistic Infections (CROI 2015), Seattle, USA, 23-26 February 2015, Poster No. 978LB.

35. Baeten JM, Haberer JE, Liu AY, Sista N. Preexposure prophylaxis for HIV prevention: Where have Baeten JM, Haberer JE, Liu AY, Sista N. Preexposure prophylaxis for HIV prevention: Where have
we been and where are we going? J Acquir Immune Defic Syndr 2013;63(Suppl 2):S122-S129. [http:// dx doi.org/10.1097/QAI.0b013e3182986f69]

36. Pettifor A, Nguyen N, Celum C, et al. Tailored combination prevention packages and PrEP for young key populations. J AIDS Soc 2015;18(Suppl 1):19434. [http://dx.doi.org/10.7448/IAS.18.2.19434]

37. AVAC, Global Advocacy for HIV Prevention, New York City, USA. Combination prevention. http:// www.avac.org/infographic/defining-combination-prevention-ongoing-trials-sub-saharan-africa (accessed 10 October 2015).

38. USAID. USAID announces microbicide awards. 6 August 2015. https://www.usaid.gov/what-we-do/ global-health/hiv-and-aids/technical-areas/microbicides-providing-hiv-prevention-option/2015microbicide-awards (accessed 18 October 2015).

39. PEPFAR: The US President's Emergency Plan for AIDS Relief, the Bill \& Melinda Gates Foundation, and the Nike Foundation partner on $\$ 210$ million initiative to reduce new HIV infections in adolescent girls and young women. 1 December 2014. http://www pepfargov/press/releases/2014/234531 htm (accessed 18 October 2015).

Accepted 19 October 2015. 